\title{
El legado Fernández de Avilés y Alvarez - Ossorio en la Universidad Autónoma de Madrid
}

Juan Blánquez Pérez

Helena Jiménez Vialás

Universidad Autónoma de Madrid

\section{Resumen}

El presente trabajo constituye un avance de los trabajos que se están desarrollando en la Universidad Autónoma de Madrid en torno al estudio del Legado documental de Augusto Fernández de Avilés y Álvarez-Ossorio, donado en 1998 por su familia a esta institución universitaria.

Debidamente informatizado en 14 bases de datos, generadas específicamente para este archivo, sus cerca de 10.000 registros constituyen hoy clara evidencia de la intensa actividad científica llevada a cabo por el citado arqueólogo en sus casi 40 años de actividad profesional. Sendos corpora sobre escultura ibérica y romana, Diarios de Excavaciones, algunos de ellos todavía inéditos, de las numerosas excavaciones que llegó a realizar, un archivo fotográfico personal con más de 900 imágenes entre negativos y positivos, o la correspondencia mantenida con numerosos investigadores, tanto nacionales como extranjeros, constituyen una apretada muestra de lo que guarda este Legado.

El estudio del mismo está previsto que culmine en un libro a publicar en la Serie Varia que se edita en esta misma Universidad Autónoma y pretende constituir, tal y como constará en su título, un merecido homenaje a su persona y a su obra.

\section{Palabras clave:}

Fernández de Avilés, Biografía, Legado, bases de datos, fotografía, diarios de excavaciones, Cerro de los Santos

Résumé:

Dans ce travail on présente l'état du projet de recherche qu'on devéloppe actuellement à l'Université Autónoma de Madrid sur l'archive documentaire de l'archéologue Augusto Fernández de Avilés y Álvarez-Ossorio, dont la famille a fait don en 1998 à cette Université.

L'archive a été digitalisé et catalogué grâce à 14 bases de données, crées spécifiquement pour ce projet-là. Les plus de 10.000 enregistrements prouvent aujourd'hui la très importante activité scientifique dont cet archéologue a été responsable dans les plus de 40 ans d'activité scientifique. On y retrouve, par exemple, deux corpora sur la sculpture ibérique et romaine, quelques Journaux de Fouilles des nombreux fouilles qu'il a dirigé et qui restent parfois inédits, un archive photographique personnel de plus de 900 images entre les négatives et les positives, ou sa correspondance avec des nombreux chercheurs espagnols et étrangers. Tout ce genre de renseignements montre aujourd'hui la richesse de cette donation documentaire.

L'étude que l'Université Autonoma a entrepris finira avec un livre que sera édité dans la série Varia du Département de Préhistoire et Archéologie, et dont le but est de bien saisir la figure scientifique et personnel du chercheur ainsi que lui donner un juste hommage.

Mots clés.

Fernández de Avilés, Biographie, Donation documentaire, base de données, photographie, journal de fouilles, Cerro de los Santos.

1 Este trabajo forma parte del Proyecto de Investigación Estudio arqueológico del legado documental Fernandez de Avilés y Alvarez-Ossorio de la Universidad
Autónoma de Madrid (06/007/2003) subvencionado por la Dirección General de Investigación de la Consejería de Educación de la Comunidad de Madrid. 


\section{1- GÉNESIS Del LegAdo:}

Hace ya siete años que se encuentra depositado en esta Universidad Autónoma el Legado documental de D. Augusto Fernández de Avilés y ÁlvarezOssorio. En efecto, el 23 de abril de 1998 y en presencia del entonces Rector Raúl Villar Doña Asunción Delgado, viuda del arqueólogo y archivera de profesión, donó generosamente este importante conjunto documental testimonio material de toda una vida dedicada al quehacer arqueológico.

Se ponía con ello broche final a una investigación que vio sus frutos un año después (1999) con la publicación de una Memoria de Licenciatura (Sánchez, 1999) centrada en el Cerro de los Santos. En concreto, en la campaña de excavación de 1963 llevada a cabo por Fernández de Avilés y cuyos materiales, por diferentes avatares -entre otros el propio fallecimiento de su excavador- permanecían inéditos depositados en el Museo de Albacete. La búsqueda de un posible Diario de Excavación, intuible por el siglado de las cerámicas con claras referencia a "cortes" y "estratos" nos llevó a contactar con la familia Fernández de Avilés y, en último lugar, con su viuda, Doña Asunción (Blánquez y Sánchez, 1999, 221 y ss.).

Si la donación de este Legado en la Universidad Autónoma favoreció, de modo inmediato, la culminación con éxito del citado estudio en torno al santuario ibérico de El Cerro de los Santos (Sánchez, 2002) y, paralelamente, el desarrollo de una línea de investigación en torno al archivo documental de Fernández de Avilés pronta a terminar en un libro homenaje (Blánquez, 2006), la repercusión del Legado ha sido mayor de lo prevista. Hasta el punto de haber inspirado el inicio de una línea específica

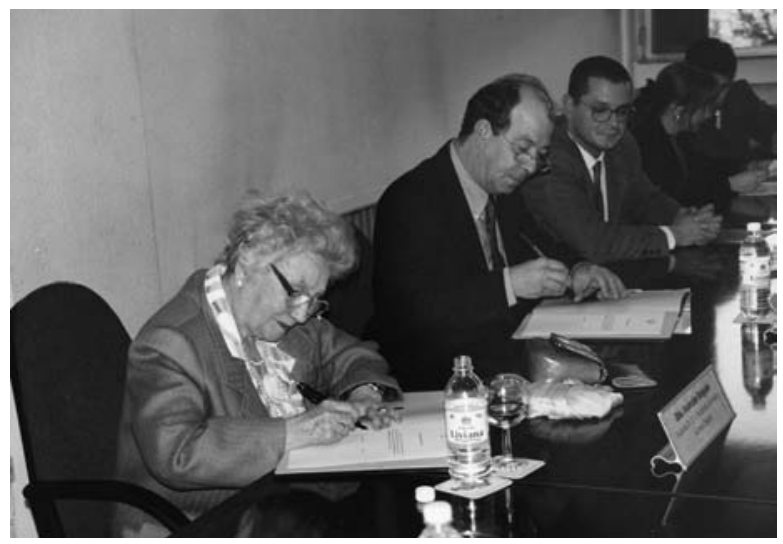

1. Doña Asunción Delgado en el acto de donación del Legado a la Universidad Autónoma de Madrid, el 23 de abril de 1998, siendo Rector D. Raúl Villar. de investigación, creemos que inédita, en la universidad española (Blánquez, 2000; Blánquez y Roldán, 1999a y 1999b; Eodem 2000; Blánquez y Rodríguez, 2004), atenta a los estudios historiográficos de la arqueología española: el estudio de la fotografía antigua -de sus imágenes, si queremos ser más precisos (González Reyero, 2005). La existencia dentro del Legado de un significativo archivo fotográfico con cerca de 900 negativos de distinto formato y soporte (cristal y gelatino bromuro), así como numerosas copias en papel -en la actualidad todas ellas digitalizadaspermite una detallada revisión de sus campañas de excavaciones en yacimientos, caso del Cerro de los Santos (Sánchez Gómez, 2002); o, más recientemente, Iuliobriga, El Redal, o El Cabecico del Tesoro (campaña de 1935).

\section{Augusto Fernández de Avilés y Alvarez-Osorio. Una Biografía Pen- DIENTE}

D. Augusto Fernández de Avilés y ÁlvarezOssorio nació en Madrid en 1908. Hijo del entonces bibliotecario del Palacio Real Fernández de Avilés y García Alcalá-, y sobrino de Francisco Álvarez-Ossorio y Farfán de los Godos que llegó a ser director del Museo Arqueológico Nacional, se educó en un ambiente intelectual especialmente cuidado en contacto, ya desde pequeño, con la arqueología. Dichas circunstancias, indudablemente, influyeron en lo que sería su futura actividad profesional.

Cursó sus primeros años en el colegio Alfonso $X I I$ de El Escorial y, posteriormente, hizo el bachiller en el instituto Cardenal Cisneros. Estudió Filosofía y Letras en la entonces Universidad Central, donde se licenció en 1930. Un año después, con tan sólo 23 años, ingresó mediante oposición en el Cuerpo Facultativo de Archiveros, Bibliotecarios y Arqueólogos. A raíz de ello se trasladó a Murcia (1932) como director de su museo provincial -cargo que ocupó hasta 1941- para regresar a Madrid e incorporarse, ya de manera definitiva hasta su muerte, en el Museo Arqueológico Nacional.

A lo largo de aquellos nueve años en el Museo Provincial Artístico Arqueológico de Murcia llevó a cabo una más que notable labor profesional, tanto de investigación como docente universitaria e institucional. Para entonces no habían pasado ni 20 años de la primera excavación oficial realizada en la provincia de Murcia (1923) en el santuario de $\mathrm{Ntr}^{\mathrm{a}} \mathrm{Sr}^{\mathrm{a}}$ de La Luz subvencionada "por S. M El Rey" (García Cano, 1999, 76). Para la importante labor que llevó a cabo en favor del patrimonio murciano contó en 


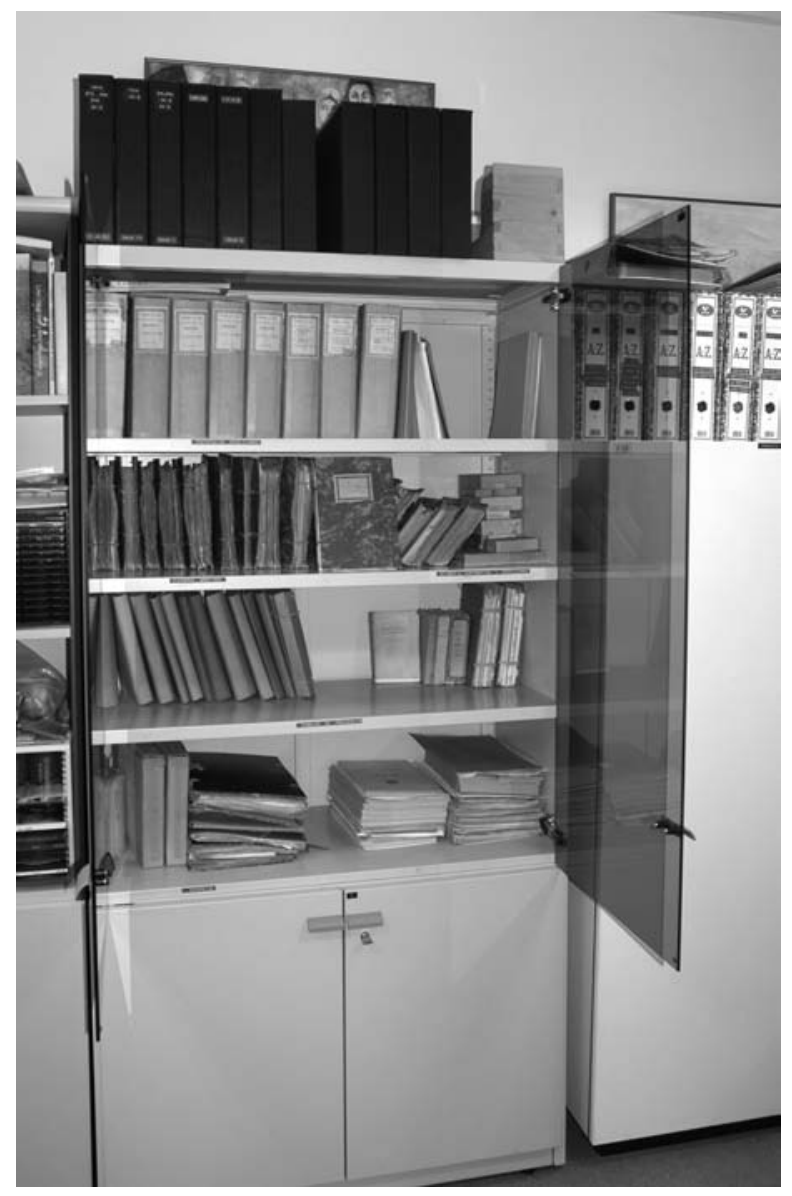

2. El Legado Fernández de Avilés, actualmente en la Facultad de Filosofía y Letras de la

Universidad Autónoma de Madrid.

aquellos años con la colaboración de Cayetano de Mergelina. Este investigador, por encargo de la Junta Superior de Excavaciones (1934), había iniciado la excavación de la basílica del Llano del Olivar (Algezares) a la que siguió el mausoleo de La Alberca (1935). Dichas actividades marcaron el inicio de una estrecha colaboración entre ambos que cuajaría en la conjunta excavación, en aquel mismo año, de la necrópolis de El Cabecico del Tesoro (Verdolay). Sin embargo, el inicio de la guerra civil al año siguiente impidió la continuidad de aquellos trabajos de campo (Navarro, 1999, 21; Quesada, 2000, 62 y ss).

La llegada de Fernández de Avilés al museo de Murcia supuso, verdaderamente, todo un revulsivo para la institución. Fue entonces cuando se llevó a cabo la primera catalogación de los fondos del museo que llevaba más de 20 años inaugurado (1910). También a él se debió la creación de un archivo fotográfico de sus materiales más representativos, corpus de imágenes éste que vino a unirse a los ya existentes del Museo Provincial de Bellas Artes y del Servicio de
Defensa del Patrimonio Artístico (Fernández de Avilés, 1942a, 97, 102 y ss.).

Pronto asumió cargos de indudable responsabilidad en favor de la protección y estudio del rico patrimonio murciano que, por aquel entonces, incluía administrativamente la provincia de Albacete. Así, fue Asesor Provincial del Servicio de Recuperación y Defensa del Patrimonio Artístico Nacional, o Comisario Provincial de la Comisaría General de Excavaciones Arqueológicas, nada más finalizar la guerra (junio de 1939), hasta 1941. Paralelamente, desarrolló toda una labor docente como Profesor Ayudante en las cátedras de Historia de la Cultura e Historia del Arte en la Universidad de Murcia entre 1931 y 1936- y, finalizada la contienda, Profesor Auxiliar en la segunda de las cátedras. Aquel cargo lo ocupó hasta 1941, momento en que se trasladó nuevamente a Madrid.

Numerosos artículos de prensa -cerca de 50 guardados hoy en el Legado- dan testimonio de su intensa actividad científica y celo profesional, no sólo en cuestiones puramente arqueológicas sino también artísticas y de divulgación, tanto de Murcia capital como de su provincia. Valga como ejemplo el título del publicado el 14 de abril de 1934 en La Verdad "Sobre estética urbana", En defensa del tesoro artístico murciano. Sus primeras colaboraciones con la prensa se remontan a 1933 y, excepto en los años de la guerra, ésta fue ininterrumpida hasta su regreso a Madrid pero, incluso entonces, aun de manera más esporádica, sus artículos en la prensa murciana -El Tiempo, Levante Agrario y La Verdad- se prolongaron hasta 1948. Posteriormente, ya de 1962 y 1963, se conservan en el Legado tres colaboraciones directamente relacionadas con sus trabajos en el Cerro de los Santos. Aparecieron publicadas en $\mathrm{La}$ Voz de Albacete y La Verdad de Murcia, respectivamente.

En aquellos años llevó a cabo sucesivas excavaciones, bien como director, bien en colaboración, pero en cualquiera de los casos asumiendo notable responsabilidad en los trabajos como se observa tras la lectura de Diarios de Campo por él redactados. Prospectó en 1933 en la necrópolis ibérica de El Cabezo del Tío Pío (Archena), donde llegó a realizar "una pequeñísima cata" (Fernández de Avilés, 1943, 116), si bien no pudo corroborar los datos apuntados años atrás (192224) por Juan Cabré y en 1935 los citados trabajos en el Cabecico del Tesoro que, tras finalizar la contienda bélica, pasaron a ser dirigidos por Gratiniano Nieto.

Paralelo a las excavaciones propiamente dichas llevó a cabo frecuentes prospecciones por 
diferentes términos municipales. Así, en 1935 prospectó en el poblado minero iberorromano de La Unión (Fernández de Avilés, 1942b, nota 2 en p. 137); en 1935 y, posteriormente, en 1940 en el Castillo de Los Garres (Fernández de Avilés 1947, 257 y s.) situado en la cercanía de la propia Murcia; o en Fortuna, concretamente en el Castillejo de los Baños y el Castillico de las Peñas. Las notas y Diarios manuscritos, tanto de excavación como de prospección, redactados con la minuciosidad en él tan característica cobran hoy especial valor al haber permanecido algunos de ellos inéditos. Así, el Legado guarda en la actualidad los Diarios de las excavaciones en la necrópolis ibérica de El Cabecico del Tesoro (campaña de 1935); los castros prerromanos de Monte Cantabria y El Redal, ambos en Logroño, de 1945; la Cueva de Peña Forúa, con materiales tardorromanos, de 1946 y del santuario ibérico de El Cerro de los Santos (Montealegre del Castillo, Albacete), en concreto las campañas de 1962 y 1963).

En diciembre de1941, mediante concurso, se trasladó a Madrid a trabajar en el Museo Arqueológico Nacional en calidad de Jefe de la Sección de la Edad Antigua y en esta institución trabajó hasta su muerte ocupando sucesivos cargos de responsabilidad. De hecho, llegó a ser su Director interino -“accidental", como a él le gustaba decir- los dos últimos años de su vida, por encargo del entonces director general de Bellas Artes Gratiniano Nieto (Herrera, 1968). Su fallecimiento impidió la confirmación oficial de su nombramiento definitivo al cargo para el que ya, en 1967, había redactado la correspondiente Memoria ${ }^{2}$.

A lo largo de casi tres décadas llevó a cabo una silenciosa -pero efectiva- gestión en dicha institución, si bien sin abandonar por ello la investigación y su labor docente, esta última en la Universidad Complutense. Así, fue profesor Ayudante entre 1942 y 1949 en la cátedra de García y Bellido, donde impartió Arqueología General y Arqueología Clásica. Su sólida formación científica y metodológica, así como el trabajar en tan diferentes -si bien complementarias- instituciones, indudablemente tuvo que favorecerle poder investigar con solvencia, tanto en el campo del arte como de la arqueología, y dentro de ésta, en los periodos ibérico, romano, medieval. No obstante, fue en la arqueología ibérica y

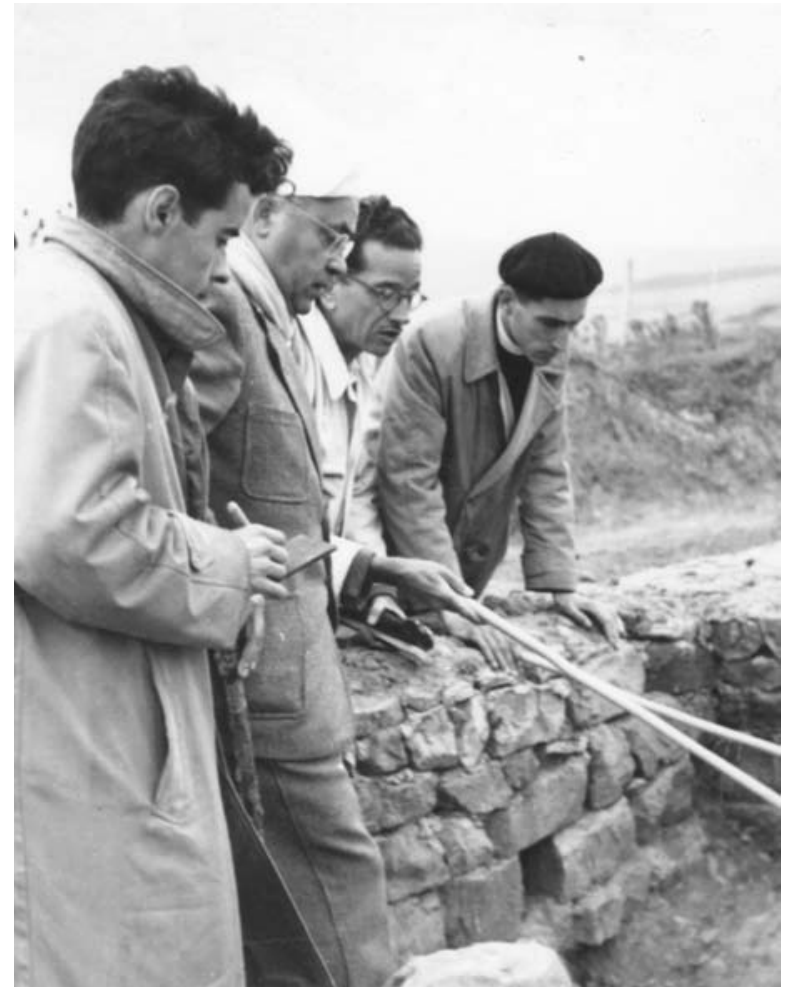

3. Fernández de Avilés con García y Bellido en las excavaciones de Iuliobriga (Reinosa, Santander). (Legado Fernández de Avilés, U.A.M.; $\mathrm{n}^{\mathrm{o}}$ inv.0505).

romana donde sus trabajos obtuvieron mayor alcance. De hecho, su estudio sobre la escultura ibérica del Cerro de los Santos -tema central de su tesis doctoral- así como las excavaciones, que dirigió en el propio santuario en colaboración con Sánchez Jiménez (1962 y 1963), se pueden considerar modélicas para su época (Sánchez, 2002, 38 y ss.) al estar impregnadas de un incuestionable modernismo en cuanto a su razonamiento científico (Nicolini, 1999, 113).

Al año de su vuelta a Madrid (1942) ya era becario y, poco después, colaborador del instituto de arte Diego Velázquez. En 1946 ocupó el cargo de Secretario de la revista Archivo Español de Arqueología (1946) creada y dirigida por su maestro García y Bellido. Años después, en 1952, pasó a ser Jefe de Sección del recién creado instituto Rodrigo Caro (Sánchez 2002, 30). Su vinculación al mismo y a la citada revista la mantuvo hasta su fallecimiento en abril de 1968, de ahí que el propio García y Bellido escribiera su necrológica tras 27 años consecutivos de tan leal
2 En el Legado Fernández de Avilés se conserva el original mecanografiado -con anotaciones personales- de la Memoria sobre cuestiones de Museología, Legislación y Bibliografía y en especial sobre la función y gobierno del Museo
Arqueológico Nacional redactada con motivo del Concurso para la provisión de la plaza de Director del Museo Arqueológico Nacional. Madrid 1967 
colaboración (García y Bellido, 1968, 3-4).

Tal y como comentábamos, en 1949 se doctoró en la universidad madrileña bajo la tutela de Antonio García y Bellido con el citado estudio sobre El Cerro de los Santos. Aportación al estudio de la escultura Ibérica. Su labor profesional en el Museo Arqueológico le había permitido manejar "directamente la riquísima colección escultórica de Montealegre", por entonces en curso de reorganización. Consciente de la existencia de errores en las antiguas catalogaciones y de esculturas apenas estudiadas, o el valorar -como él llamaba- "los objetos no plásticos con ellas aparecidos (...) la posibilidad, incluso, de repetir las investigaciones sobre el terreno"... debieron determinar el que acometiera un estudio monográfico del yacimiento y, muy en particular, sobre su escultura en piedra. Como él mismo defendería en la introducción de su tesis "Cumpliremos con ello el frustrado propósito (...) del divulgador del arte autóctono hispano, Mr. Paris, y cumpliremos también, después de Don J. R. Mélida, la vieja deuda que con la más preclaras y simbólicas de nuestras antigüedades teníamos contraída"3.

$\mathrm{Su}$ nueva etapa en Madrid no significó un parón en sus trabajos de campo, todo lo contrario. En 1943 excavó en el castro prerromano vizcaíno de Navárniz (Taracena y Fernández de Avilés, 1945); en 1945 en los también castros de Monte Cantabria y El Redal, ambos en la provincia de Logroño y en colaboración con Blas Taracena, si bien su fallecimiento impidió que colaborara en la redacción de los avances (Fernández de Avilés, 1956, 2) a las correspondientes Memorias (Fernández de Avilés, 1959); en 1946 en la cueva de Peña Forúa (Guernica, Vizcaya). Su estrecha colaboración profesional y de amistad con García y Bellido favoreció, sin duda, el que participara durante años en las excavaciones de éste. Ejemplos de ello serían las sucesivas campañas de Iuliobriga (1953-56) que, con el tiempo (1957 y 58), llegó a codirigir en la práctica junto con M. A. García Guinea (Iglesias, 2004, 194); o en Herrera de Pisuerga en 1960 y 1961 (García y Bellido et alii, 1962) y las Fontes Tamarici (Velilla del Río Carrión), ambas en la provincia de Palencia (Fernández de Avilés, 1961; Id., 1964a; García y Bellido y Fernández de Avilés, 1961).

En 1962 y 1963 llevó a cabo sus dos últimas campañas de campo. Fue la excavación del ya citado santuario ibérico de El Cerro de los Santos llevada a cabo en colaboración con, el entonces

3 Trascripción literal de la $2^{\text {a }}$ redacción (ampliada) mecanografiada de su tesis doctoral, páginas 1 y 2 . En el director del museo provincial de Albacete, J. Sánchez Jiménez (Fernández de Avilés 1964b; Id., 1965; Id., 1966). La iniciativa partió del Director General de Bellas Artes del Ministerio de Educación y Ciencia, Gratiniano Nieto, a raíz de la aparición de nuevos restos escultóricos en el cerro para, con ello, dejar en evidencia que el yacimiento no estaba agotado. De hecho, las piezas que aparecieron en aquellas dos campañas configuran hoy el núcleo principal escultórico del Cerro de los Santos en el Museo de Albacete (Ruiz, 1989, 77 y 199 y ss.).

$\mathrm{Su}$ sólida formación científica, así como sus conocimientos idiomáticos por encima de la

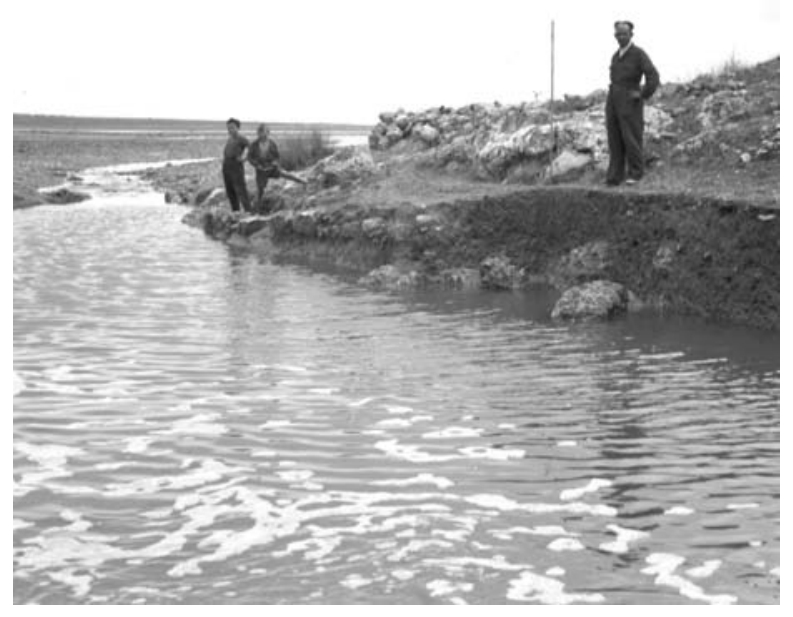

4. La Rambla del judío, junto al santuario ibérico del Cerro de los Santos (Montealegre del Castillo, Albacete), durante la excavación de 1963 (Legado Fernández de Avilés, U.A.M.; n ${ }^{\mathrm{O}}$ inv.0435).

media en aquella época, le permitieron realizar viajes y estancias formativas en sucesivas instituciones extranjeras europeas y americanas, o impartir periódicamente cursos y seminarios. Así, valgan como ejemplos, el representar al instituto Diego Velázquez en el I Congresso di Studi Liguri de Bordighera (1950), su estancia como becario de intercambio -durante casi medio añoen el Institut of Fine Arts de New York (1951), o sus cursos sobre Historia del Arte en el Instituto de Cultura Hispánica o en la escuela de Artes Aplicadas y Oficios Artísticos, etc.

Numerosos títulos y su pertenencia a instituciones científicas certifican hoy el notable reco-

Legado se guarda también una copia de la $1^{\mathrm{a}}$ redacción, con parte gráfica incluida. 
nocimiento de su labor investigadora: Académico fundador de la Universidad Alfonso X El Sabio de Murcia; miembro de la Assosiaçao dos Arqueologos Portugueses, de Lisboa; miembro del Deustches Archaeologisches Institut de Berlín...

Las investigaciones de Fernández de Avilés abarcaron muy diversas áreas de la arqueología española, con el mérito añadido de estar, en su mayor parte, publicadas. El Legado conserva hasta un total de 221 obras suyas que incluyen libros, capítulos de libros, artículos, recensiones, necrológicas, así como numerosas colaboraciones en la prensa local. Todas ellas, como decíamos, abordaron temáticas tan variados como la arqueología púnica, ibérica, o hispanorromana, la museografía, el arte sacro, etc. (Jiménez Vialás, 2005). Cronológicamente, podría hablarse de dos etapas diferenciadas a lo largo de su producción: la década de los años 30 en que, como director del museo de Murcia, publicó fundamentalmente sobre temas culturales centrados en el sureste y, desde su vuelta a Madrid (1941) hasta su muerte (1968), cuando la temática de sus estudios se diversifica. Si bien mantuvo el interés por aquella área, sus publicaciones a partir de entonces reflejaron también la labor llevada a cabo en el Museo Arqueológico Nacional y sus excavaciones ya en norte peninsular.

\section{El legado Fernández de Avilés}

El Legado donado a la Universidad Autónoma de Madrid vino ya, previamente, con una primera ordenación acometida por su viuda -no en balde era archivera- estructurado en seis bloques referidos a conceptos amplios: 1.-Preparación de oposiciones, 2.-Ficheros gráficos, 3.-Epigrafía, Numismática y Oposiciones, 4.-Trabajos en preparación, 5.-Separatas, y 6.-Fotografías.

Aun con ello, para la necesaria informatización y futura consulta por la comunidad científica era necesaria una mayor concreción/matización de los bloques preestablecidos. Ello nos ha llevado a establecer -hasta la fecha- un total de 14 categorías basadas -únicamente- en la valoración del tipo de documento y, no tanto, en periodos culturales o disciplinas científicas. Todo ello ha quedado ordenado en 14 "bases de datos" que lo articulan y catalogan: 1. Correspondencia: cartas, sobres, y postales escritas; 2. Fotografía: fotografías, pruebas de imprenta y fotolitos; 3. Dibujos: dibujos, croquis y planos; 4. Trabajos en preparación: textos de investigación, tanto inéditos como algunos, incluso, publicados; 5. Publicaciones: libros y separatas exclusivamente por él redactadas; 6. Otras Publicaciones: libros y separatas de otros autores guardadas en el Legado; 7. Prensa: recortes de prensa, tanto colaboraciones suyas como referidas a importantes hallazgos arqueológicos; 8. Notas: pequeñas referencias bibliográficas, fichas sobre piezas o yacimientos, etc.; 9. Docencia: programas de asignaturas por él impartidas, listados de alumnos, etc.; 10. Diarios: notas personales de sus trabajos de campo; 11 . Ficheros gráficos: imágenes sobre temas estudiados; 12. Apuntes oposiciones; 13. Material Tesis; 14. Varios: Guías turísticas, folletos, etc.

El establecimiento de estas categorías partió, como es lógico, de una primera clasificación lle-

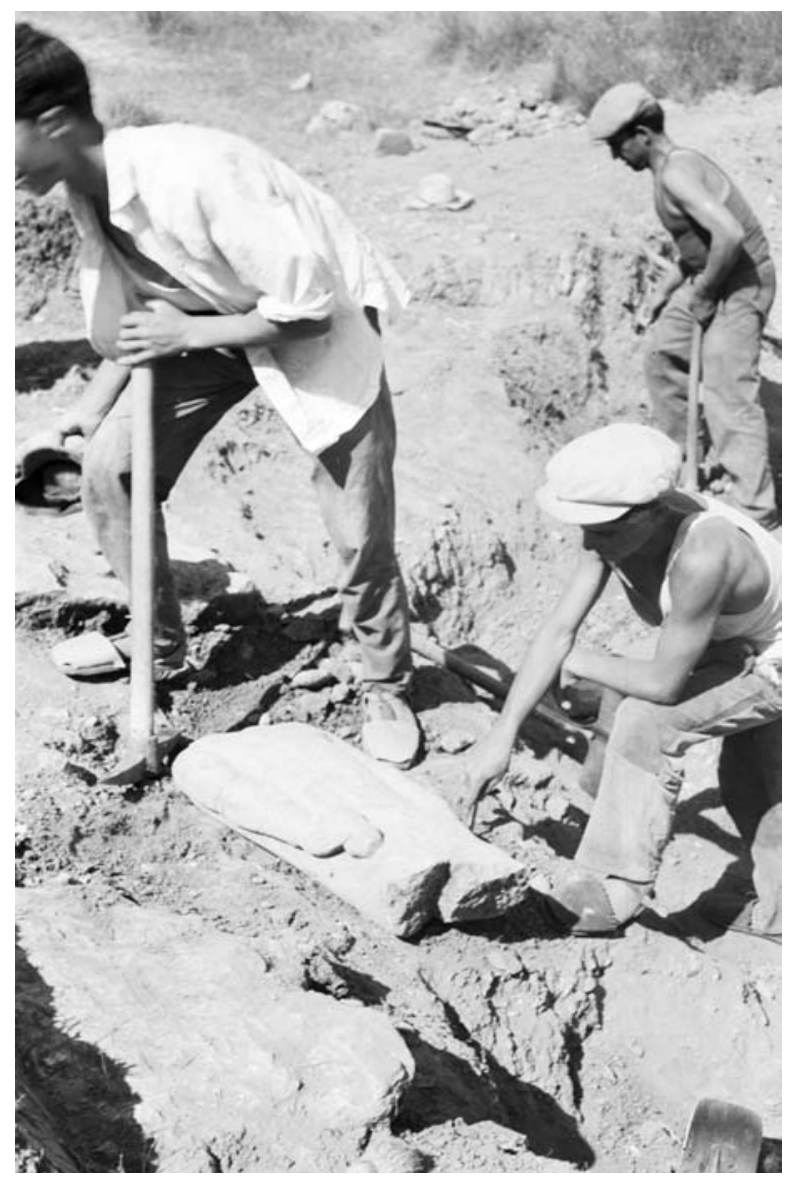

5. Momento de aparición de una escultura en la excavación del Cerro de los Santos. Campaña de 1962. (Legado Fernández de Avilés, U.A.M.; no inv.0486).

vada a cabo en el momento del ingreso del Legado en la Universidad Autónoma de Madrid (Blánquez y Sánchez, 1999, 225) pero que diferenciaba, solamente, siete tipos documentales. No obstante, conscientes de la importante labor de catalogación acometida, en su día, por Dña. Asunción, las 14 bases de datos actuales llevan incorporadas el campo Ubicación original en las que se referencia la ubicación/clasificación primigenia de todos los documentos que constitu- 
yen el Legado.

Los campos que articulan cada una de las bases de datos responden a dos necesidades básicas: por un lado, inventariar y reubicar cada uno de los documentos; por otro, catalogar de la

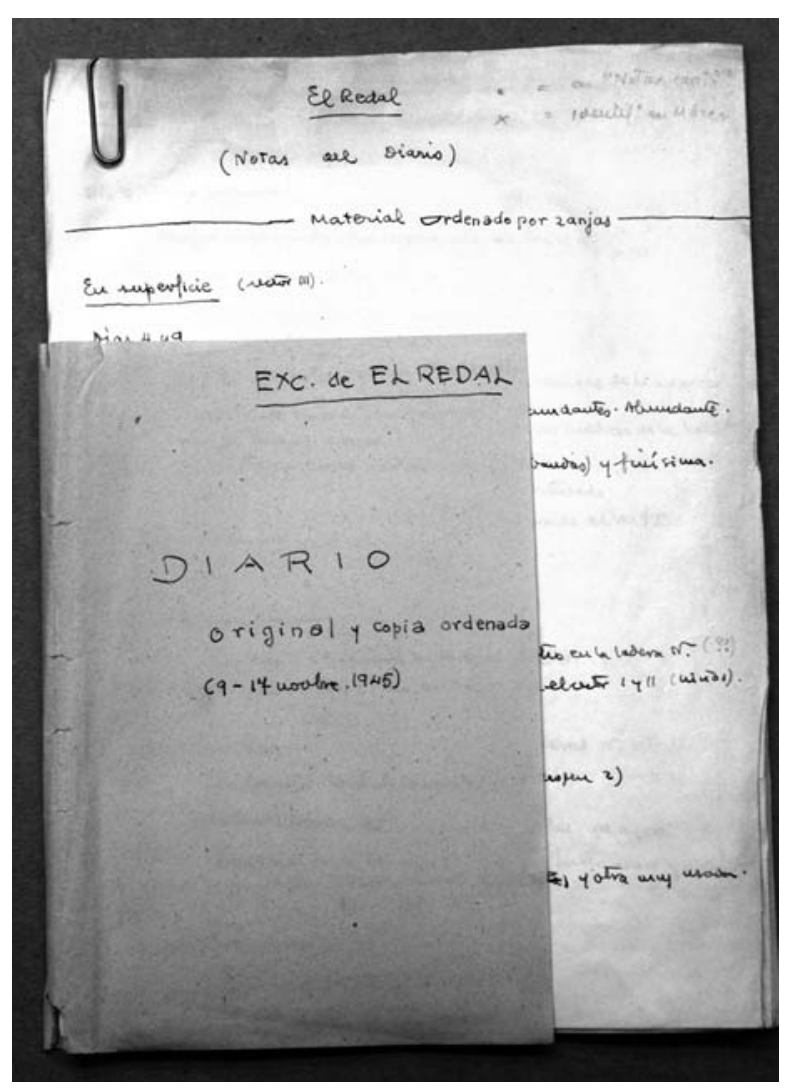

6. Diario de Excavaciones de El Redal (Logroño), campaña de 1945 (Legado Fernández de Avilés, U.A.M.; $\mathrm{n}^{\mathrm{O}}$ inv.0586).

manera más completa posible los citados documentos. La primera de ellas ha quedado resuelta por los campos: $N^{o}$ de inventario, Archivador, Ubicación original, Ruta, Se relaciona con y, por último, Observaciones. Son estos seis campos comunes a todas las bases de datos pero, lógicamente, las obvias peculiaridades de cada documento han quedado recogidas en nuevos campos, esta vez específicos. Han sido los casos, por ejemplo, de Remitente para la base de datos Correspondencia, el de Técnica para la base de datos Dibujos, o el de Editorial para las bases de datos Publicaciones y Otras publicaciones.

Mención aparte merece el campo Concepto, presente en todas las bases de datos pero con un diferente significado en cada una de ellas, al constituir el inicio ya de su interna clasificación. Sirvan como ejemplo el de Correspondencia, donde se diferencia entre postal escrita, carta o sobre recibido, copia de su original...; el de Fotografía, donde se especifica si se trata de una fotografía, una prueba de imprenta, un fotolito...; el de Dibujo, donde se clasifica entre dibujo, croquis, plano, apunte...; o el de Varios, donde se diferencia entre guía, postal sin escribir, currículo o folleto.

La definición, tanto de las bases de datos como de sus respectivos campos, partió de la experiencia obtenida en trabajos similares acometidos con anterioridad como, por ejemplo, recientemente, el archivo documental de Antonio García y Bellido (Blánquez y Pérez Ruiz, 2004). No obstante, algunos otros surgieron durante el normal desarrollo de la catalogación propiamente dicha casos, por ejemplo, de las bases de datos Otras Publicaciones, Docencia o Ficheros gráficos.

Un ilustrativo ejemplo de las bases de datos generadas es, posiblemente, la referida a Correspondencia, con hasta un total de 16 campos generados. Veámoslo con detalle:

\section{$N^{o}$ de inventario:}

corresponde al número de inventario del Legado. Se ha definido siempre con cuatro dígitos utilizando, para ello, cuantos ceros a la izquierda sean necesarios dado el carácter informático del soporte (Ejemplo: 0002).

\section{Archivador:}

número de archivador en que se ha guardado, de manera definitiva, el documento en cuestión dentro del Legado.

\section{Ubicación original:}

hace referencia a la ubicación antigua del documento, resultado de la antigua ordenación realizada por su viuda.

Ruta:

código alfanumérico que ubica el documento dentro de la estructuración general del Legado.

Concepto:

especifica si se trata si es una postal escrita, carta recibida, sobre recibido, copia de su original, etc.

Fecha: referencia de cuando el documento fue generado. Explícita si aparece en el propio documento, o implícita si se puede saber por otra vía. Si se conocen todos los datos, se escribe día y mes siempre con dos dígitos y el año completo (Ejemplo: 15/03/1959).

\section{Remitente:}

hace referencia a la persona que envía la carta. En el caso de que el autor sea 
Fernández de Avilés, se especifica como Fdez. de Avilés. Si el autor es otro, se especifican nombre y apellidos.

\section{Formato:}

define el formato del soporte, si se trata de folio, holandesa, cuartilla, DIN-A4, o medidas sin tipificar (alto y ancho en centímetros).

\section{Escritura:}

especifica el tipo, bien mecanografiada, bien manuscrita.

$N^{0}$ de hojas:

especifica el número de las mismas que compone el documento.

Imagen:

hace referencia a la temática de la misma -postal, etc.- en el caso de que el documento la lleve.

Notas al margen:

indica si el documento las tiene, o no, si están al margen, etc.

Carácter:

hace referencia a si el documento es oficial o personal.

Temática:

trata el tema del documento.

\section{Se relaciona con:}

aclara si tiene relación directa con otro documento. En caso positivo especifica de qué tipo es e incluye, entonces, su $\mathrm{N}^{\mathrm{o}}$ inv. [Ejemplo: $N^{0}$ inv. 0958 (fotografía)].

\section{Observaciones:}

añade características particulares del documento como anotaciones, correcciones, idioma en que está escrito, etc.

Las otras diez bases de datos restantes, tal y como se ha apuntado, contienen en gran medida estos campos pero incluyen, además, otros específicos que caracterizan -ya con detalle- cada tipo de documento. Así, en base de datos Fotografía, además de los ya citados, se añaden:

- Autor: corresponde al autor del documento gráfico. En los casos en que el autor es Fernández de Avilés viene especificado como Fdez. de Avilés. Ahora bien, en los casos en los que el autor es otro, se especifican nombre y apellidos.

- Soporte: determina el soporte de la imagen, bien gelatina, papel, nitrato, placa de vidrio, etc.

- Medidas y Medidas de las copias: hacen refe- rencia al tamaño de las fotografías, ya sean originales o copias, expresada en $\mathrm{cm}$ ). En el caso de que se conserve en el Legado más de una copia, pero con diferentes medidas, se especifica entre paréntesis el número de copias de la citada medida.

- $\quad N^{0}$ de copias: detalla el número que se conserva de una misma fotografía (con medidas similares), siempre sin contar el primer documento.

- Yacimiento: hace referencia al nombre del mismo y su pedanía, en caso de existir.

- Término municipal: hace referencia al mismo y a su provincia.

- Título: recoge la referencia presente en la fotografía, si lo hubiere, especificando si se encuentra en el reverso o margen de la imagen (Ejemplo: Dama oferente).

- Publicada: apunta si está inédita, o no.

- Pone en caja: reproduce, en caso de haber tenerlo, el título original escrito en la caja donde se guardaba el documento.

- El campo Imagen en esta base de datos de Fotografía concreta si la imagen fotográfica es de un positivo o de un negativo.

La base de datos Dibujos sólo añade un campo nuevo a los anteriores: Técnica. Alude, en esta ocasión que alude a aquélla empleada para a si éste está realizado a lápiz, a tinta, o a bolígrafo.

Por el contrario, en las bases de datos Publicaciones y Otras Publicaciones han sido varios los campos específicos añadidos. Han sido Revista, en referencia a la cita bibliográfica completa donde fue publicada; Editorial, donde se

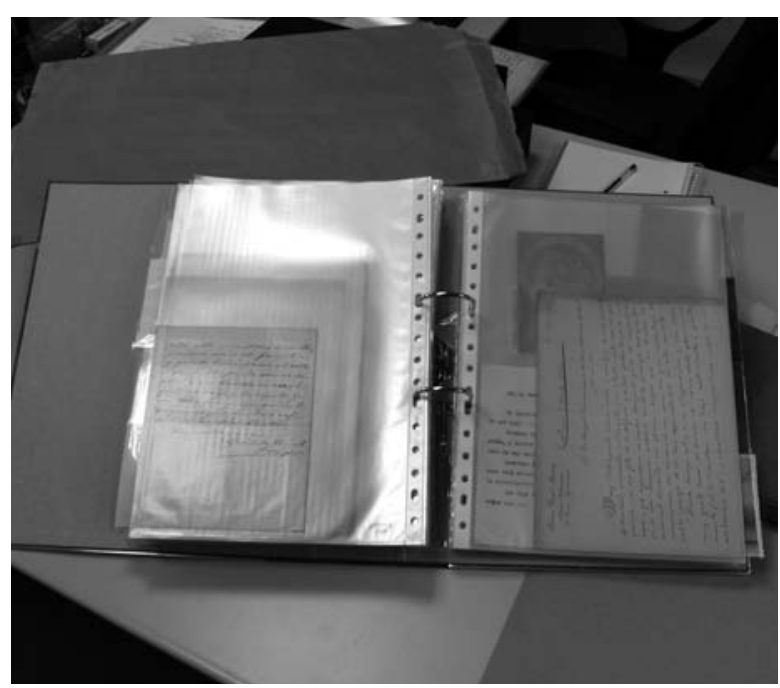

7.- Catalogación y archivado actual de la documentación del Legado Fernández de Avilés. 
publica el libro y lugar de la misma y, por último, $N^{0}$ de Ejemplares, que especifica el número de ejemplares de una misma publicación que se conserva en el Legado.

Las bases de datos restantes - Trabajos en preparación, Prensa, Notas, Docencia, Diarios, y Varios- no incluyen ya ningún campo específico diferente a los indicados como ejemplo inicial en la base de datos Correspondencia.

Con toda esta labor de informatización y nuevo archivado de la totalidad de los documentos se quiere facilitar la futura consulta del Legado y asegurar, paralelamente, una mejor conservación. Una vez terminado el estudio del mismo está previsto su traslado definitivo a la Biblioteca de Humanidades de esta Universidad Autónoma.

\section{Conclusiones}

Sirvan, pues, estas líneas, como apretado resumen de los trabajos de inventario, catalogación y estudio, prontos a finalizar, llevados a cabo en el Legado de Fernández de Avilés. La totalidad de los resultados obtenidos, fruto de un trabajo en común de un grupo interdisciplinar e interinstitucional, verán la luz a finales del presente año en un próximo libro que se editará en esta misma universidad, a través de su Serie Varia. Dicha publicación constituirá, pensamos, un merecido homenaje, tanto a la persona como a la obra científica de este investigador.

Tras ello, el Legado Fernández de Avilés está previsto se traslade, ya de manera definitiva, a la Biblioteca de Humanidades de la UAM donde, gracias a la informatización y nuevo archivado de la totalidad de los documentos, quedará abierto a su consulta a cuantos investigadores lo necesiten. Quizás ello, además, favorezca el generar una inercia que a toda la comunidad científica beneficiaría: la donación de nuevos legados referidos a las investigaciones llevadas a cabo por antiguos estudiosos de las muy distintas ramas del Saber aglutinadas, todavía hoy, en esta facultad de Filosofía y Letras de la Universidad Autónoma. Que así sea.

\section{Bibliografía.}

BLÁNQUEZ PÉREZ, J., Edt. Cfco. (2000): 100 imágenes. Pasado y presente de la Arqueología española. Madrid

BLÁNQUEZ PÉREZ, J. (Ed. Ctfco), (2006): Augusto Fernández de Avilés y Álvarez-Ossorio. En homenaje. En Serie Varia 6 (e.p.).

BLÁNQUEZ PÉREZ, J. y PÉREZ RUIZ, M. (2004): "El archivo documental de Antonio García y Bellido". En Blánquez, J. y Pérez, M. (eds.), Antonio García y Bellido y su legado a la arqueología española. Serie Varia 5, 295-310.

BLÁNQUEZ PÉREZ, J. y ROLDÁN GÓMEZ, L., Eds. Cficos (1999a): La Cultura ibérica a través de la fotografía de principios de siglo. Vol.I.- Un homenaje a la memoria. Madrid.

BLÁNQUEZ PÉREZ, J. y ROLDÁN GÓMEZ, L., Eds. Cficos (1999b): La Cultura ibérica a través de la fotografia de principios de siglo. Vol.I.- Las colecciones madrileñas. Madrid.

BLÁNQUEZ PÉREZ, J. y ROLDÁN GÓMEZ, L., Eds. Cficos (2000): La Cultura ibérica a través de la fotografía de principios de siglo. Vol.II.- El litoral mediterráneo. Madrid.

BLÁNQUEZ PÉREZ, J. y RODRÍGUEZ NUERE, B., Coords. (2004): El arqueólogo Juan Cabré (1882-1947). La fotografía como técnica documental. Madrid.

BLÁNQUEZ PÉREZ, J. y SÁNCHEZ GÓMEZ, Mª.L. (1999a): "El Legado Fernández de Avilés y ÁlvarezOssorio". En Blánquez, J. y Roldán, L. (eds.), La Cultura Ibérica a través de la fotografía de principios de siglo. Vol.I: Un homenaje a la memoria. Madrid, 221231.

FERNÁNDEZ DE AVILÉS Y ÁLVAREZ-OSSORIO, A. (1942a): "Museo Arqueológico de Murcia I y II". Memorias de los Museos Arqueológicos Provinciales 1941 (Extractos). Cuerpo Facultativo de Archiveros, Bibliotecarios y Arqueólogos. Inspección General de Museos Arqueológicos. Madrid, 97-118.

FERNÁNDEZ DE AVILÉS Y ÁLVAREZ-OSSORIO, A. (1942b): "El poblado minero, iberorromano, del Cabezo Agudo, en La Unión”. Archivo Español de Arqueología 47, 136-152.

FERNÁNDEZ DE AVILÉS Y ÁLVAREZ-OSSORIO, A. (1943): "Notas sobre la necrópolis ibérica de Archena (Murcia)". Archivo español de Arqueología 50, 115-121.

FERNÁNDEZ DE AVILÉS Y ÁLVAREZ-OSSORIO, A. (1947): "Poblado iberorromano del "Castillo de los Garres" (Murcia)", tirada aparte de la Crónica del III Congreso Arqueológico del Sudeste Español, Murcia, 256260.

FERNÁNDEZ DE AVILÉS Y ÁLVAREZ-OSSORIO, A. (1956): "Excavaciones en Logroño (1945). Monte Cantabria y El Redal”. Berceo 40, Logroño, 328-343.

FERNÁNDEZ DE AVILÉS Y ÁLVAREZ-OSSORIO, A. (1959): "Excavaciones en El Redal (Logroño). Campaña de 1945”. V Congreso Arqueológico Nacional, Zaragoza, 160-166. 
FERNÁNDEZ DE AVILÉS Y ÁLVAREZ-OSSORIO, A. (1961): "Prospección arqueológica en las "Fontes Tamarici" (Velilla, Palencia)". Revista de Archivos, Bibliotecas y Museos LXIX, 1, Madrid.

FERNÁNDEZ DE AVILÉS Y ÁLVAREZ-OSSORIO, A. (1964a): "Investigaciones Arqueológicas en Palencia”. Noticiario Arqueológico Hispánico VI, Cuadernos 1-3, Inspección General de Excavaciones Arqueológicas, Madrid, 391-394.

FERNÁNDEZ DE AVILÉS Y ÁLVAREZ-OSSORIO, A. (1964b): "Excavaciones en el Cerro de los Santos (1962) (1)". Noticiario Arqueológico Hispánico VI, Cuadernos 1-3, 1962, Inspección General de Excavaciones Arqueológicas, Madrid, 152-156.

FERNÁNDEZ DE AVILÉS Y ÁLVAREZ-OSSORIO, A. (1965): "Excavaciones en el Cerro de los Santos $\left(2^{\text {a }}\right.$ Campaña)". Noticiario Arqueológico Hispánico VII, Cuadernos 1-3, 1963, Madrid, 143-145.

FERNÁNDEZ DE AVILÉS Y ÁLVAREZ-OSSORIO, A. (1966): "Cerro de los Santos. Montealegre del Castillo (Albacete). Primera Campaña, 1962". Excavaciones Arqueológicas en España 55, Madrid

GARCÍA Y BELLIDO, A. y FERNÁNDEZ DE AVILÉS, A. (1961): "Fuentes Tamaricas. Velilla del Río Carrión (Palencia)". Excavaciones Arqueológicas en España 29, Inspección General de Excavaciones Arqueológicas, Madrid.

GARCÍA Y BELLIDO, A.; FERNÁNDEZ DE AVILÉS, A.; BALIL, A. y VIGIL, M. (1962): "Memoria de las excavaciones arqueológicas efectuadas en Herrera de Pisuerga. I Campaña 1960”. Excavaciones Arqueológicas en España 2, Inspección General de Excavaciones Arqueológicas, Madrid.

GARCÍA Y BELLIDO, A., (1968): "Augusto Fernández de Avilés y Álvarez-Ossorio”. Archivo Español de Arqueología 41, 117-118, 3-4.

GARCÍA CANO, J. M., (1999): “Cayetano de Mergelina y los orígenes de los estudios ibéricos en Murcia”. En Blánquez, J. y Roldán, L. (eds.), La Cultura Ibérica a través de la fotografía de principios de siglo. Vol.I: Un homenaje a la memoria. Madrid, 75-78.

GONZÁLEZ REYERO, S., 2005: La aplicación de la fotografía a la arqueología en España (1860-1960). 100 años de discurso arqueológico a través de la imagen, Universidad Autónoma de Madrid. Tesis Doctoral microfilmada.
HERRERA ESCUDERO, M ${ }^{\mathrm{a}}$ L., (1968): "Necrológica. Ilustrísimo Señor Don Augusto Fernández de Avilés y Álvarez-Ossorio". Separata (sin paginar).

IGLESIAS GIL, J.M., (2004): "El sentido de las excavaciones del profesor García y Bellido en Iuliobriga". En Blánquez, J. y Pérez, M. (eds.), Antonio García y Bellido y su legado a la arqueología española. Serie Varia 5, 187-202.

JIMÉNEZ VIALÁS, H., (2005): "Bibliografía de Augusto Fernández de Avilés y Álvarez-Ossorio". En Blánquez, J. (ed.), Augusto Fernández Avilés y ÁlvarezOssorio.En Homenje. Serie Varia 6 (e.p.).

NAVARRO, F.J., 1999: "Cayetano de Mergelina o una fe para actuar”. En Noguera, J.M. (cood.), Arquitectura de la Antigüedad Tardía en la obra de C. de Mergelina. Los mausoleos de La Alberca y Jumilla. Murcia, 13-34.

NICOLINI, G. (1999): "En torno a los estudios ibéricos. Un homenaje a D. Augusto Fernández de Avilés y Álvarez-Ossorio”. En Blánquez, J. y Roldán, L. (eds.), La Cultura Ibérica a través de la fotografía de principios de siglo. Vol.II: Las colecciones madrileñas. Madrid, 111-114.

QUESADA SANZ, F. (2000): "Las primeras excavaciones en la necrópolis ibérica de El Cabecico del Tesoro (Verdolay, Murcia)". En Blánquez, J. y Roldán, L. (eds.), La Cultura Ibérica a través de la fotografía de principios de siglo. Vol.III: El litoral mediterráneo. Madrid, 61-69.

SÁNCHEZ GÓMEZ, Ma.L. (2002): El santuario de El Cerro de los Santos (Montealegre del Castillo, Albacete). Nuevas aportaciones arqueológicas. Instituto de Estudios Albacetenses. Serie I. Ensayos Históricos y Científicos 136. Albacete.

TARACENA, B. y FERNÁNDEZ DE AVILÉS, A. (1945): Memoria sobre las excavaciones en el castro de Navárniz (Vizcaya). Junta de Cultura de la Excelentísima Diputación de Vizcaya. Madrid. 